\title{
Neurocirurgia como arte. Filosofia e perspectivas profissionais
}

\author{
Evandro de Oliveira ${ }^{1}$
}

\author{
Palestra dirigida aos jovens neurocirurgiões no 20 Encontro de \\ Neurocirurgiões Jovens da Sociedade de Neurocirurgia do Estado \\ de São Paulo (Sonesp), São Paulo, SP, março de 2006.
}

Quando o tema da minha palestra foi escolhido, não pensei em falar que, sendo neurocirurgiões, estávamos próximos de ser artistas, nem era minha intenção traçar qualquer comparação entre a arte e a nossa profissão. Embora, por vezes, essa comparação seja inevitável, tais reflexões partem da premissa de que qualquer um pode viver a vida como arte. Quando pretendemos nos superar, não podemos nunca ser passivos; devemos sempre tentar ser artistas em tudo aquilo que fizermos.

Foi difícil encontrar uma definição que esclarecesse o significado de arte, na medida em que a maior parte das definições trata da maneira como a arte é expressa ou realizada e não da arte em seu sentido estrito. Arte, como a entendemos, é algo extraordinário da alma e que, unido à verdade pessoal de cada um, exprime a singularidade do indivíduo. Na vida, nada é verdadeiramente significativo se não nascer da alma.

Assim, o tema Neurocirurgia como arte foi escolhido porque acreditamos que tudo aquilo que fizermos deve ser feito com amor, com alma e deve ser representativo do que somos e acreditamos ser nossa verdade. Deve ser feita como arte!

Embora em domínios diferentes, são exemplos de arte reger uma orquestra sinfônica ou realizar uma neurocirurgia. Pelo seu trabalho, o maestro e o cirurgião podem transmitir seus sentimentos, suas experiências pessoais e suas concepções de beleza e perfeição.

De modo bem peculiar, a determinação e a habilidade em concentrar-se em seu trabalho, aliadas ao sentido de percepção desses indivíduos, podem tornar inigualável o seu desempenho em determinadas áreas. A perícia do cirurgião ou a regência do maestro são representações de sua singularidade.

Atributos inatos não podem ser aprendidos, mas podem certamente ser desenvolvidos ao limite se, com trabalho e persistência, dirigirmos nossa energia física e mental em direção a um objetivo único. Aqueles que têm a habilidade de associar o que lhe é inato, seus impulsos e motivações, à paixão de realizar e evoluir estão destinados a sobressair em qualquer circunstância. Na neurocirurgia, como em qualquer profissão, dedicação tenaz, imaginação e individualidade são atributos dos que têm sucesso. Mas, para ser artista em nossa profissão, o neurocirurgião necessita de algo além dessas qualidades.

Artistas são indivíduos intensos e resolutos, providos de imaginação ímpar e construtiva, cuja inspiração primeira deriva do amor que têm por tudo o que fazem.

Dedicação e amor vêm lado a lado na vida dos que ambicionam o melhor e devem sempre ser as virtudes do neurocirurgião. Cada paciente e cada cirurgia têm histórias próprias, que oferecem ao cirurgião a oportunidade única de aprender, desenvolver conhecimentos, aprimorar 
sua destreza, fortalecer a sua crença numa técnica ou estimular sua curiosidade e imaginação para a criação de novas técnicas.

A versatilidade em quebrar regras e encontrar vias alternativas para solucionar situações novas ou diferentes é resultado de curiosidade, imaginação, experiência e, principalmente, conhecimento.

$\mathrm{O}$ cérebro é único em sua natureza complexa e delicada. Como o escultor aprende a adaptar a força do seu formão à resistência do material que utiliza, o cirurgião não pode se esquecer de como o cérebro é frágil e sensível a manipulações inadequadas. Assim, por meio de seu conhecimento e sua técnica microcirúrgica, o neurocirurgião expressa na cirurgia sua arte ao trabalhar com aquele que é, com certeza, o mais delicado e precioso dos materiais. O cérebro é a obraprima da criação, o templo de nossos pensamentos, a mais complexa estrutura viva do nosso Universo e, provavelmente, o mais perfeito e o mais belo instrumento de arte produzido pelas mãos divinas.

Quando nós, neurocirurgiões, ajudamos a natureza a curar suas doenças, nos tornamos também artesãos. E esse é o nosso grande privilégio. Assim, o neurocirurgião deve ter persistência para dominar os mais sutis detalhes da técnica operatória e ter profundo conhecimento das ciências neurológicas básicas.

Avanços científicos e novas tecnologias constantemente nos fornecem novo instrumental, certamente muito útil, mas apenas instrumentais não transformam ninguém em um neurocirurgião competente. Apenas quando estivesse familiarizado com a complexidade da arquitetura cerebral e com os processos de seu funcionamento é que o cirurgião deveria ter o direito de realizar uma cirurgia.

O conhecimento das ciências neurológicas e da anatomia microcirúrgica é essencial à neurocirurgia. $\mathrm{O}$ neurocirurgião deve ter preparo em matérias básicas, na neurologia clínica e na investigação laboratorial. Mas, acima de tudo, deve aprender a manipular o instrumento principal de nossa profissão, a neuroanatomia microcirúrgica.

Todos os nomes célebres da história da neurocirurgia não foram produtos da sala de operações apenas. Embora não haja dúvidas sobre suas qualidades cirúrgicas inatas, todos compartilham a qualidade de serem mestres em neurociências e em neuroanatomia.

Nesta era da microneurocirurgia, com tantos avanços tecnológicos, métodos diagnósticos inovadores e criação de novas abordagens cirúrgicas, é inconcebível que o conhecimento inestimável de neurociências e de técnicas microcirúrgicas seja ainda menosprezado. Os computadores de hoje fornecem imagens tridimensionais em perspectiva da anatomia do cérebro, mas o conhecimento da anatomia microcirúrgica adquirido no laboratório ainda permanece insuperável. Associado à percepção íntima do neurocirurgião, ele cria uma nova quarta dimensão, compreensível apenas para os que já a experimentaram.

Neurocirurgiões devem ter versatilidade para aceitar mudanças científicas e técnicas que provavelmente terão grande papel no futuro, mas devem também ser extremamente cautelosos antes de aceitar qualquer inovação. Instrumentais sofisticados e toda a parafernália computadorizada são tão-somente instrumentos que auxiliam a mão do homem a desempenhar a dificílima tarefa de operar o cérebro de um ser humano.

A tecnologia tem, com certeza, seu lugar na neurocirurgia, mas não podemos nos deixar esquecer da cirurgia propriamente dita. Estaríamos abandonando nossos ideais e trocando a arte pelo aparato computadorizado. Estaria sendo esquecida a arte de operar e manusear o delicado tecido nervoso.

Como neurocirurgiões, devemos contemplar o que fizemos em passado não tão distante e nos perguntar se, de fato, já exploramos todas as possíveis fronteiras que a anatomia e as técnicas microcirúrgicas abriram à neurocirurgia.

Quantos entre nós realmente conhecem a craniotomia pterional, uma das mais elegantes abordagens da neurocirurgia, descrita pelo professor Yasargil há mais de trinta anos? Quantos entre nós compreendem suas etapas lógicas, ou podem descrever giros, sulcos, cisternas e nomear as estruturas vasculares e neurais expostas nessa abordagem? Quantos sabem utilizar os sulcos e os espaços cisternais para navegar no interior do cérebro com sua técnica microcirúrgica?

Embora usados diariamente na prática neurocirúrgica, esses e muitos outros procedimentos ainda têm suas possibilidades reais subestimadas. Será que conhecemos, ou realmente já exploramos, todo o potencial da cirurgia até seus limites? Quem responder "sim" a essa questão é um cirurgião que perdeu seus horizontes ou que não progrediu com o tempo.

Como os processos de concepção e raciocínio são provavelmente uma das maiores características da mente humana, nós não vemos limite à imaginação do artista. Um verdadeiro artista na neurocirurgia, com experiência e espírito aberto, pode vislumbrar detalhes mínimos que contribuam, em cada procedimento cirúrgico, à melhora dos resultados.

Assim, o compromisso com a excelência cria a maneira de exprimirmos a nossa arte e singularidade. $\mathrm{O}$ conhecimento adquirido na busca cotidiana de respostas torna cada novo trabalho mais próximo da perfeição.

Não, ainda não exploramos todo o potencial da cirurgia, e ainda muitos entre nós estão longe de ser artistas. Persistência em ser o melhor no que fizermos e a paixão de fazer o melhor que pudermos só admi- 
tem uma justificativa, e esta não é a de sermos artistas. Acredito que o neurocirurgião deva encontrar o sentido de sua vida ao pé do leito de seus pacientes, sempre acreditando numa arte e no Deus que criou os homens, e não em um Deus que os homens criaram por si mesmos. Se nós O colocarmos em nossa arte e em tudo o que criamos, nós $\mathrm{O}$ encontraremos em tudo o que fizermos e no que nos aconteça.

Que este seja o significado de nossas vidas, nossa ambição e nossa crença: que a força de nossas vidas que nos faz desejar ser o melhor no mundo o seja para tornarmos o mundo melhor.

Na medicina, como na arte, só o melhor é o suficiente. A idéia da beleza imaculada que o cérebro encerra em sua complexa arquitetura e o amor ilimitado ao próximo, que luta para sobreviver, são as inspirações primordiais do cirurgião em sua tentativa de recriar a arte divina, aquela que o próprio Senhor criou.

Por fim, quero dizer algumas palavras aos que me ajudaram e que são, de certa forma, responsáveis por estes conceitos de arte e vida.
Olhando o mar de minha janela pude ver os movimentos revoltos do farol, como uma tocha, enviando fachos de luz sobre o mar. Isso me trouxe à lembrança as pessoas que me ajudaram durante a vida. As luzes do farol impedem que os navios colidam contra rochedos ou obstáculos perigosos à beira-mar. Os que nos ajudam e orientam em nossa jornada são também luzes que nos previnem dos desastres e frustrações, permitindo que cheguemos ao porto, isto é, que, no confronto com pessoas e situações, evitemos rochedos ou obstáculos.

Olhando para trás, agora posso ver o bem que tantos me fizeram, principalmente pela arte da amizade. Alguns não estão mais conosco nesta terra, mas ainda posso alcançar a todos com minha gratidão. Posso a eles erguer minhas preces e também seguir seus exemplos, fazendo por outros o bem que fizeram por mim. Exemplo não é a melhor maneira de ensinar, é a única maneira, já disseram.

Meus amigos, podemos abandonar este mundo, mas nunca nossos ideais. Isso é a verdadeira arte da vida. Isso é o que torna a vida uma arte. 